\title{
Osteonecrosis of the jaws in a patient with multiple myeloma - a case report
}

\author{
Vera Lúcia Duarte da Costa Mendes, ${ }^{1}$ Fabiana de Paoli, ${ }^{1}$ Wagner Hespanhol ${ }^{1}$ \\ 'Service of Dentistry, Arthur Siqueira Cavalcanti Institute (HEMORIO), Rio de Janeiro, RJ, Brazil \\ - Conflicts of interest: none declared.
}

Abstract

Objective: this paper reports a case of osteonecrosis of the jaws associated with the use of intravenous bisphosphonates (BRONJ) after extraction of the maxillary right first and second molars. Case report: a 53-year-old male patient with diagnosis of multiple myeloma undergoing treatment at Arthur Siqueira Cavalcanti Institute (HEMORIO) with intravenous bisphosphonate (zoledronic acid), performed dental extractions in a private clinic. Approximately one month later, he complained of pain at the dental extraction site and was referred by the oncologist to the hospital's dental service. Intraoral clinical examination revealed an extensive area with characteristics of bone necrosis and the panoramic radiography revealed a radiolucent area suggestive of bone sequestration. The combination of clinical and radiographic findings confirmed the diagnosis of bisphosphonate-related osteonecrosis of the jaws (BRONJ). Conclusion: patients under regular continuous use of bisphosphonates must be warned of the possible development of BRONJ after invasive dental procedures and proper guidance must be provided.

Keywords: Multiple myeloma; Bisphosphonates; Osteonecrosis.

\section{Introduction}

$\mathrm{M}$ ultiple myeloma is a cancer of plasma cells, which are the cells that produce antibodies (immunoglobulins). A malignant or cancerous plasma cell is called myeloma cell. The term "multiple" myeloma is used because frequently multiple portions or areas of the bone are affected, presenting as a tumor and/or an area of bone loss. ${ }^{1}$

The treatment for myeloma in symptomatic patients includes induction therapy, which is performed with the use of chemotherapic agents and high-dose chemotherapy with hematopoietic stem cell transplantation. In some cases, conservative radiation can be used to preserve the bone marrow and support therapy with medication for pain, bisphosphonates, growth factors and antibiotics. ${ }^{2}$

In dentistry, bisphosphonates are the major source of concern for treating patients with multiple myeloma. They are stable synthetic analogs of pyrophosphate and bind selectively to active zones of bone resorption, decreasing osteoclastic activity and incorporating to the mineral structure (residual effect) over a long period. This medication attenuates bone pain and decreases the osteolytic activity of the disease, improving the clinical condition. However, since 2003, there have been reports of osteonecrosis of the jaws associated with the use of intravenous bisphosphonates, such as pamidronate and zoledronate, which are administered to patients with multiple myeloma, mostly preceded by dentoalveolar surgical procedures. ${ }^{3}$

Marx et al. ${ }^{3}$ defined osteonecrosis of the jaws as a clinical entity characterized by a region of exposed necrotic bone in the maxillofacial area, which persists for more than eight weeks without healing, in patients who have used or are using bisphosphonates and who have no history of cer- vicofacial radiation therapy. The most common signs and symptoms are pain, edema, erythema, exudate, ulcerations, fistulas and tooth mobility (Table 1).

Table 1. Stages of bisphosphonate-related osteonecrosis of the jaws (BRONJ) and their treatments

Stages of bisphosphonate-related osteonecrosis of the jaws (BRONJ) and treatments

\begin{tabular}{c|c|c}
\hline Stage & Clinical presentation & Conduct \\
\hline Risk & No bone exposure & $\begin{array}{c}\text { Instructions to the } \\
\text { patient }\end{array}$ \\
\hline
\end{tabular}

Instructions to the pa-

Asymptomatic bone exposure with small soft tissue inflammation tient, mouthwashes with antibacterial solutions and careful follow-up.

Instructions to the patient, mouthwashes

Bone exposure accompanied by pain, inflammation or infection of with antibacterial solutions, superficial bone debridement and careful follow-up.

\begin{tabular}{l|l|l} 
adjacent soft tissue & $\begin{array}{l}\text { debridement and careful } \\
\text { follow-up. }\end{array}$ \\
\hline 3 & $\begin{array}{l}\text { Bone exposure accom- } \\
\text { panied by pain, inflam- } \\
\text { mation or infection of } \\
\text { adjacent soft tissue, } \\
\text { with possibility of } \\
\text { osteolysis, extending to } \\
\text { the lower border of the } \\
\text { mandible or patho- } \\
\text { logical fractures and } \\
\text { extraoral fistulas. }\end{array}$ & $\begin{array}{l}\text { Instructions to the } \\
\text { patient, mouthwashes } \\
\text { with antibacterial solu- } \\
\text { tions, palliative surgeries } \\
\text { and careful follow-up. }\end{array}$ \\
\hline
\end{tabular}

Source: Rugierro SL et al., 2009 apud Brozoski et al., 2012, p. 267 
The risk factors for the development of bisphosphonate-related osteonecrosis of the jaws (BRONJ) are mainly associated with the drug (potency and duration of therapy), surgical procedures, cancer diagnosis and anti-cancer therapies, presence of other comorbidities, glucocorticoid therapy, excessive use of alcohol and/or tobacco, and history of concomitant oral disease. ${ }^{4}$

Although the exact mechanism of the appearance of BRONJ is unknown, it is believed to be related to the presence of bacteria, decreased bone remodeling, and antiangiogenic effects of bisphosphonates. ${ }^{5}$

The mandible and the maxilla are richly vascularized bones with intense remodeling, which results in a high bisphosphonate concentration. The decrease in bone remodeling produces an acellular bone that may be secondarily infected due to microtraumas that occur in the oral mucosa. ${ }^{6}$

This paper reports the clinical management of a patient with multiple myeloma under treatment with bisphosphonate (zoledronate) for approximately 12 months, who developed osteonecrosis of the jaws after dental extractions.

\section{Case Report}

A 53-year-old male black patient with tetraparesia was referred to Arthur Siqueira Cavalcanti Institute (HEMORIO) in May 2015 with an intense back pain, under continued use of tramadol and suspected of having multiple myeloma.

A bone marrow biopsy was performed and a diagnosis of multiple myeloma, plasmacytoma and spinal cord compression syndrome (tetraparesia). The therapeutic regimen started with dexamethasone (10 mg bolus) + zoledronic acid (Zometa $4 \mathrm{mg} / 100 \mathrm{~mL}$ intravenous). A chemotherapy protocol was established with the use of Bortezomib and monthly cycles of intravenous zoledronic acid (Zometa).

In November 2016, the patient complained of toothache in the maxillary right region. He sought care outside HEMORIO and underwent extraction of the maxillary right first and second molars. Approximately 1 month after the extraction procedure, he was referred to the hospital's dental service by the oncologist. Intraoral clinical examination revealed an extensive area of calcified tissue with brownish coloration, well-defined margins, painless, not bleeding, with slight mobility upon touching, located in the maxillary right alveolar ridge, suggesting bone necrosis (Figure 1). A panoramic radiograph revealed a radiolucent area at the site of extractions with irregular radiopacity suggestive of bone sequestration (Figure 2). Based on the clinical and radiographic findings, the patient was diagnosed with stage III maxillary osteonecrosis, in which there is bone exposure with pain, inflammation and local contamination.

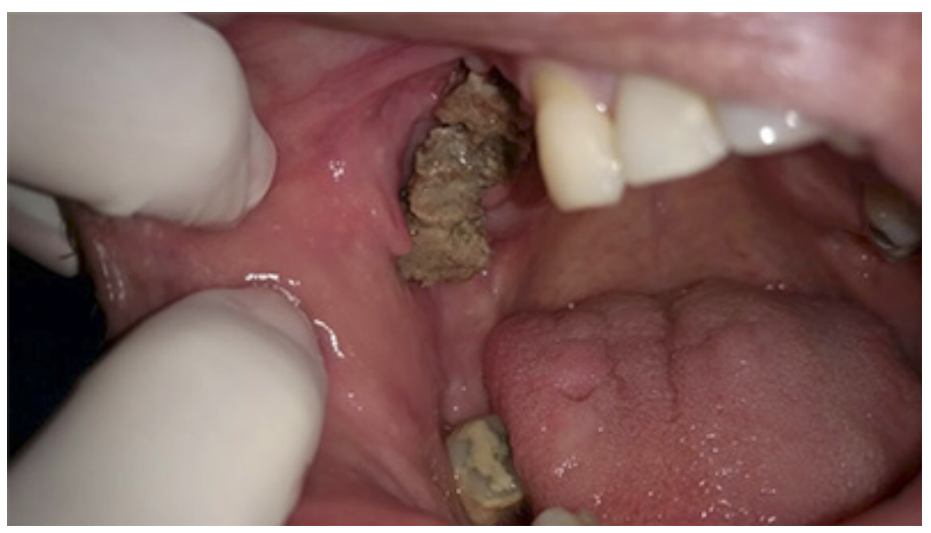

Figure 1. Initial clinical case. Extensive area of calcified tissue with brownish coloration, well-defined margins, located in the maxillary right alveolar ridge, clinically suggesting bone necrosis

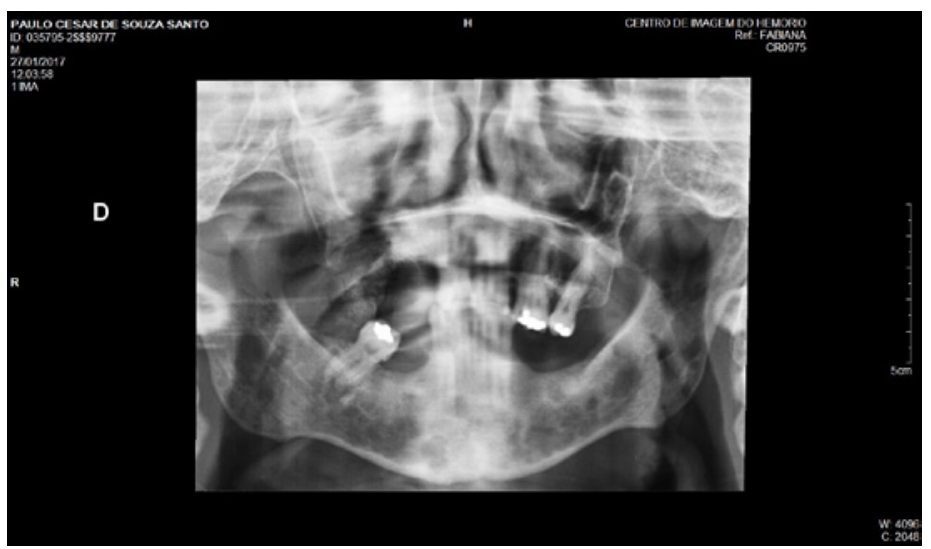

Figure 2. Panoramic radiograph. Radiolucent area at the site of extractions with irregular radiopacity, suggestive of bone sequestration

A prescription was made of oral amoxicillin $500 \mathrm{mg}+$ potassium clavulanate $125 \mathrm{mg}$ for 21 days combined with $0.12 \%$ chlorhexidine mouthrinses $12 / 12$ hours and $0.2 \%$ chlorhexidine gel for topical use three times a day. The oncologist discontinued the use of bisphosphonate (Zometa).

The patient returned for evaluation after 15 days, presenting a decrease in local inflammation, but without regression of the extensive bone sequestration area. After 30 days, the exposed bone block released spontaneously, the wound was closed by second intention (Figure 3). Patient was followed-up initially every three months, then every six months and now annually at the hospital's dental service.

Figure 3. Final clinical case. After 30 days, the exposed bone block released spontaneously, the wound was closed by second intention

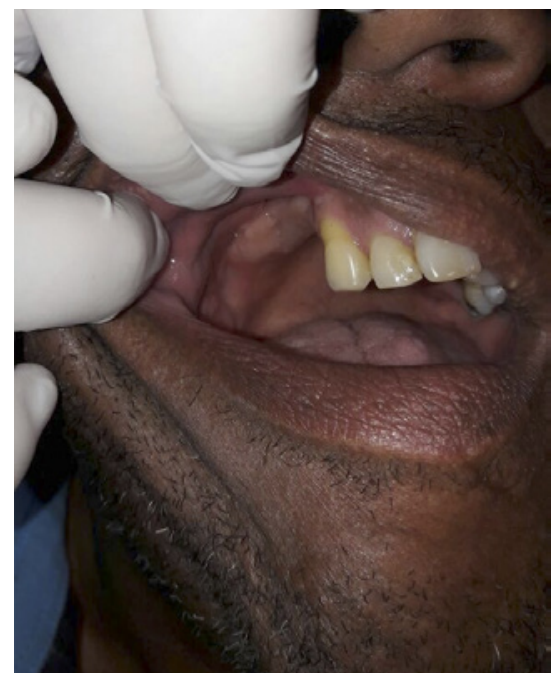




\section{Discussion}

Cancer patients and patients with metastatic bone diseases often exhibit complications including pain, pathological fracture, spinal cord compression and hypercalcemia, which cause worsening of quality of life and high morbidity and mortality rates. These alterations are usually a consequence of the metastatic process that result from osteoclast activation mediated by different cytokines produced by the tumor cells, which causes bone resorption and allows tumor growth. ${ }^{7}$

In order to control these complications, in the last years, oncologists have used medications named bisphosphonates, which are non-metabolized pyrophosphate analogs capable of depositing in the bone and inhibiting osteoclastic function. These drugs are part of the treatment protocol for patients with moderate to severe hypercalcemia associated with cancer; osteolytic lesions associated with breast cancer and multiple myeloma together with antineoplastic chemotherapy; and osteolytic lesions originating from any solid tumor. These indications have led to a massive use of bisphosphonates in most clinics and medical oncology hospitals world wide.

There are several types of bisphosphonates approved for clinical use. They are divided into generations and their antiresorptive properties increase approximately tenfold between generations of the drug. Intravenous bisphosphonates are used in cancer patients and those for oral administration are used to treat other diseases that cause bone lysis, like osteoporosis. Intravenous drugs include pamidronate (Aredia), a second-generation bisphosphonate, and zoledronic acid (Zometa), a latest-generation bisphosphonate and the most potent for clinical use. Zoledronic acid is administered once monthly, as seen in the therapeutic regimen of this case report, and can be maintained for continuous use. ${ }^{7}$

The average induction time of BRONJ in patients with intravenous zoledronic acid monthly dosing schedule is only 9 months, while for patients who use oral bisphosphonates (alendronate) the average BRONJ induction time is 30-52 months. Corroborating with the literature, the patient of our case was under an intravenous bisphosphonate regimen for 12 months. In most cases, patients undergoing bisphosphonate therapy are usually subjected to other therapies simultaneously, such as chemotherapy and administration of corticosteroids. Cytostatics and glucocorticoids may also affect healing of the surgical wound, and are considered as possible risk factors. ${ }^{3}$

As a preventive measure, patients who will initiate monthly cycles of intravenous bisphosphonates must first undergo a comprehensive and careful clinical and radiographic evaluation of the oral and dental conditions. In the present case, the oncologist did not refer the patient to evaluation by a dentist before instituting the bisphosphonate therapy.
It is absolutely essential that this information be widely disseminated and the dentist's roles include the following aspects: ${ }^{3,5,8-10}$

- Prophylaxis of dental caries and periodontal disease, as well as conservative treatments are essential for the preservation of dental structures and oral health and must be performed whenever necessary; ${ }^{3}$

- Any dentoalveolar surgery, including exodontia of teeth with short- and medium-term indication for extraction, must be performed before initiation of treatment with intravenous bisphosphonates. If the patient's systemic conditions permit, the recommendation is to postpone the initiation of intravenous bisphosphonate therapy until reepithelization of the extraction site occurs or, ideally, until tissue healing has been completed; 3,9

- In patients with removable partial dentures or complete dentures, the presence areas of trauma to the mucosa must be investigated, especially along the mylohyoid line. ${ }^{3,5}$

In patients that will initiate intravenous bisphosphonate therapy, the main objective is to minimize the risk of developing BRONJ. Whenever the systemic conditions permit to wait, bisphosphonate therapy should be delayed until the oral health conditions are impreoved..$^{10}$ This is a multidisciplinary decision that must be agreed between the attending physician, the dentist and other specialists involved in patient care.

In the present case report, the patient was undergoing regular monthly cycles of intravenous bisphosphonate (zoledronic acid - Zometa) for 12 months and, during the course of treatment, he sought a private dental clinic due to toothache and was subjected to dental extractions without informing the dentist of the use of bisphosphonate. On the other hand, the oncologist did not refer the patient to the dental service before instituting the bisphosphonate therapy.

Differently from the conduct described in this case report, it is strongly recommended that all patients undergo an appropriate preventive evaluation of the oral conditions by a dentist and receive instructions on ideal oral hygiene before initiation of bisphosphonate tharapy. ${ }^{11,12}$ Unnecessary invasive dental procedures should be avoided; when indicated, the use of bisphosphonate must be temporarily discontinued for 90 days before and after the invasive procedure (dental extraction, dental implant placement or other surgeries that involve bone manipulation). It is not necessary to discontinue the drug for routine non-invasive dental procedures. ${ }^{13,14}$

Table 1 summarizes the clinical recommendations according to the dental procedure, type of bisphosphonate therapy and patient's clinical condition. ${ }^{3}$

The treatment of BRONJ varies widely in the literature presenting multiple approaches. ${ }^{15}$ Conservative treatment includes debridement of the bone sequestration area fol- 
lowed by irrigation with saline solution and daily mouthrinsing with $0.12 \%$ chlorhexidine. Prescription of analgesics and antimicrobials can also be associated. Radical treatment involves bone resections with primary or secondary reconstructions. Hyperbaric oxygen therapy, for many authors, still has a controversial action because it is not uniformly effective in decreasing the progression of the avascular osteonecrosis process.

In cases where osteonecrosis is already installed, the main goal should be to eliminate pain, control soft and hard tissue infection, and minimize the progression of bone necrosis. ${ }^{16}$ In the present case, the treatment of choice was oral antibiotic therapy combined with use of chlorhexidine (mouthrinses and topical gel), which was successful after 30 days.

A wide variety of preoperative procedures have been proposed to prevent this complication, among which use of antiseptic mouthwashes prior to dental extraction and during alveolar wound healing, antibiotic prophylaxis, alveoloplasty and primary closure, platelet-rich plasma, ozone therapy, and limitation of the number extraction per session. However, these recommendations must be critically evaluated because there are no clinical studies confirming that these procedures can actually reduce the development of osteonecrosis of the jaws. ${ }^{17}$

\section{Conclusion}

Although several studies have addressed the subject, there is limited evidence to define the ideal treatment approach for bisphosphonate-related osteonecrosis of the jaws (BRONJ). This paper reports a case of a successful treatment, among other options. Therefore, it is mandatory that physicians and dentists are aware that a preventive conduct for patients undergoing bisphosphonate therapy will always achieve the best outcomes.

\section{References}

1. International Myeloma Foundation. www.mielomabrasil.org.

2. Sucro LV, Silva JCML, Gehlen GW, Eldin JFS, Amaral GA, Santana MAP. Mieloma múltiplo: diagnóstico e tratamento. Rev Med Minas Gerais. 2009;19(1):58-62.

3. Coelho AI, Gomes PS, Fernandes MH. Osteonecrose dos Maxilares Associada ao Uso de Bifosfonatos. Parte II: Linhas de Orientação na Consulta de Medicina Dentária. Rev Port Estomatol Med Dent Cir Maxilofac. 2010;51(3):185-91.

4. Hewitt C, Farah CS. Bisphosphonate-related osteonecrosis of the jaws: a comprehensive review. J Oral Pathol Med. 2007;36(6):319-28.

5. Sarin J, De Rossi SS, Akintoye SO. Updates on bisphosphonates and potential pathobiology of bisphosphonate-induced jaw osteonecrosis. Oral Dis. 2008;14(3):277-85.

6. Wood J, Bonjean K, Ruetz S, Bellahcène A, Devy L, Foidart JM, et al. Novel Antiangiogenic Effects of the Bisphosphonate Compound Zoledronic Acid. J Pharmacol Exp Ther. 2002;302(3):1055-61.

7. Martins MAT, del Giglio A, Martins MD, Pavesi VCS, Lascala CA. Osteonecrose dos maxilares associada ao uso de bisfosfonatos: importante complicação do tratamento oncológico. Rev Bras Hematol Hemoter. 2009;31(1):41-6.

8. Berenson JR, Hillner BE, Kyle RA, Anderson K, Lipton A, Yee GC, et al. American Society of Clinical Oncology Clinical Practice Guidelines: the role of bisphosphonates in multiple myeloma. J Clin Oncol. 2002;20(17):3719-36.

9. Ruggiero SL, Dodson TB, Assael LA, Landesberg R, Marx RE, Mehrota B. American Association of Oral and Maxillofacial Surgeons Position Paper on Biphosphonate-Related Osteonecrosis of the Jaws - 2009 Update. J Oral Maxillofac Surg. 2009; 67(5)Suppl:2-12.

10. Khan AA, Sándor GKB, Dore E, Morrison AD, Alsahli M, Amin F, et al. Canadian Consensus Practice Guiideline for Biphosphonate Associated Osteonecrosis of the Jaw. J Reumathol. 2008;35(7):1391-7.
11. Badros A, Terpos E, Katodritou E, Goloubeva O, Kastritis E, Verrou E, et al. Natural history of osteonecrosis of the jaw in patients with multiple myeloma. J Clin Oncol. 2008;26(36):5904-9.

12. Krimmel M, Ripperger J, Hairass M, Hoefert S, Kluba S, Reinert S. Does dental and oral health influence the development and course of bisphosphonaterelated osteonecrosis of the jaws (BRONJ)? Oral Maxillofac Surg. 2014;18(2):213-8.

13. Terpos E, Morgan G, Dimopoulos MA, Drake MT, Lentzsch S, Raje N, et al. International Myeloma Working Group recommendations for the treatment of multiple myeloma-related bone disease. J Clin Oncol. 2013;31(18):2347-57.

14. Terpos E, Sezer O, Croucher PI, Garcia-Sanz R, Boccadoro M, San Miguel J, et al. The use of bisphosphonates in multiple myeloma: recommendations of an expert panel on behalf of the European Myeloma Network. Ann Oncol. 2009;20(8):1303-17. 15. Santos OS, Gambirazi LM, Félix VB, Magalhães MHCG. Osteonecrose maxilar em pacientes portadores de doenças neoplásicas sob uso de bisfosfonatos Rev Bras Hematol Hemoter. 2008;30(6):501-4.

16. Ruggiero SL, Dodson TB, Assael LA, Landesberg R, Marx RE, Mehrota B. American Association of Oral and Maxillofacial Surgeons Position Paper on Medication-Related Osteonecrosis of the Jaws - 2014 Update. J Oral Maxillofac Surg. 2014;72(10):1938-56.

17. Fedele S, Kumar N, Davies R, Fiske J, Greening S, Porter S. Dental management of patients at risk of osteochemonecrosis of the jaws: a critical review. Oral Dis. 2009;15(8):527-37.

18. Ruggiero S, Gralow J, Marx RE, Hoff AO, Schubert MM, Huryn JM, et al. Practical guidelines for the prevention, diagnosis, and treatment of osteonecrosis of the jaw in patients with cancer. J Oncol Pract. 2006;2(1):7-14.

\section{Mini Curriculum and Author's Contribution}

1. Vera Lúcia Duarte da Costa Mendes - DDS. Contribution: study conception and design, writing of the manuscript.

2. Fabiana de Paoli - DDS. Contribution: patient care, prescription and instructions to the patient, case follow up, writing of the manuscript.

3. Wagner Hespanhol - DDS. Contribution: case evaluation, planning of the surgery in the operating room, photographic documentation of the case, writing of the manuscript.

Submitted: 01/06/2018 / Accepted for publication: 02/20/2018

\section{Corresponding Author}

Vera Lúcia Duarte da Costa Mendes

E-mail: veradentista@hotmail.com 